Letters addressing topics of current interest or material in RESPIRATORY CARE will be considered for publication. The Editors may accept or decline a letter or edit without changing the author's views. The content of letters reflects the author's opinion or interpretation of information; their publication should not be interpreted as an endorsement by the Journal. Authors of criticized material will have the opportunity to reply in print. No anonymous letters can be published. Letters should be submitted electronically via Manuscript Central. Log onto RESPIRATORY CARE's web site at http://www.RCJournal.com.

\section{Ventilator Software Version Markedly Affects Time to Trigger and Time Delay}

In the July 2011 issue of RESPIRATORY CARE we read with great consideration the paper from Marchese et al, ${ }^{1}$ reporting the performance of 6 intensive-care ventilators currently available on the market. The present letter has no intention to contest the data reported in that paper; ${ }^{1}$ instead, we want to highlight the need to identify which versions of the ventilators' software were tested.

Table 1. Differences in Time to Trigger and Time Delay With Hamilton G5 Software Version 1.21 Versus Version 1.92

\begin{tabular}{lc}
\hline \hline Time to Trigger $(\mathrm{ms})$ & $\%$ Difference \\
PEEP $1 \mathrm{~cm} \mathrm{H} \mathrm{H}_{2} \mathrm{O} \mathrm{P}_{0.1} 2 \mathrm{~cm} \mathrm{H}_{2} \mathrm{O}$ & -15 \\
PEEP $5 \mathrm{~cm} \mathrm{H}_{2} \mathrm{O}, \mathrm{P}_{0.1} 2 \mathrm{~cm} \mathrm{H}_{2} \mathrm{O}$ & -18 \\
PEEP $1 \mathrm{~cm} \mathrm{H}_{2} \mathrm{O}, \mathrm{P}_{0.1} 4 \mathrm{~cm} \mathrm{H}_{2} \mathrm{O}$ & -15 \\
PEEP $5 \mathrm{~cm} \mathrm{H}_{2} \mathrm{O}, \mathrm{P}_{0.1} 4 \mathrm{~cm} \mathrm{H}_{2} \mathrm{O}$ & -11 \\
Time Delay $(\mathrm{ms})$ & \\
PEEP $1 \mathrm{~cm} \mathrm{H} \mathrm{H}_{2} \mathrm{O}, \mathrm{P}_{0.1} 2 \mathrm{~cm} \mathrm{H}_{2} \mathrm{O}$ & -11 \\
PEEP $5 \mathrm{~cm} \mathrm{H}_{2} \mathrm{O}, \mathrm{P}_{0.1} 2 \mathrm{~cm} \mathrm{H}_{2} \mathrm{O}$ & -16 \\
PEEP $1 \mathrm{~cm} \mathrm{H} \mathrm{H}_{2} \mathrm{O}, \mathrm{P}_{0.1} 4 \mathrm{~cm} \mathrm{H}_{2} \mathrm{O}$ & -8 \\
PEEP $5 \mathrm{~cm} \mathrm{H}_{2} \mathrm{O}, \mathrm{P}_{0.1} 4 \mathrm{~cm} \mathrm{H}_{2} \mathrm{O}$ & -7 \\
\hline $\mathrm{P}_{0.1}=$ airway-occlusion pressure $0.1 \mathrm{~s}$ after the start of inspiratory flow & \\
\hline
\end{tabular}

As compared to the past, manufacturers are constantly improving their devices, mainly with frequent software adjustments, which are most of the time not visible to the users. As an example, one of the devices tested by Marchese et al, the Hamilton G5, has been improved by several software versions since its first release in 2007 , with substantial improvements from one version to the next.

In a recent internal evaluation, and using a 2-chamber test lung2 (Training and Test Lung, Michigan Instruments, Grand Rapids, Michigan), with chamber 1 attached to a driving ventilator, chamber 2 connected to the ventilator under test, and the 2 chambers physically connected to each other by a metal piece, we compared the performance of the G5 ventilator software version 1.21 (release date July 16, 2009) to version 1.92 (released with software 2.00 on October 22, 2010). Table 1 shows the differences in time to trigger and time delay between the 2 versions. Depending on the PEEP settings and

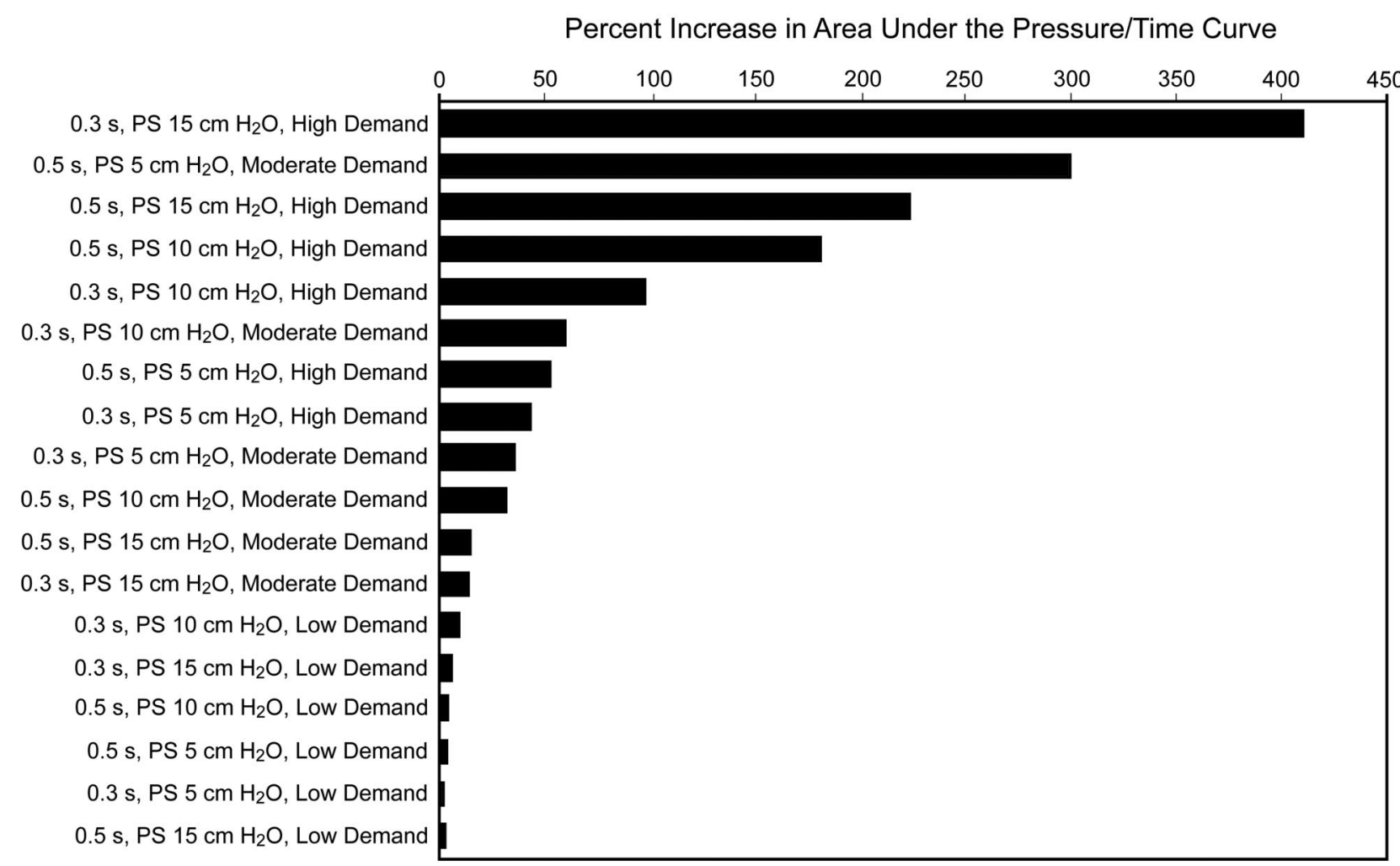

Fig. 1. Percentage differences in area under the pressure/time curve at $0.3 \mathrm{~s}$ and $0.5 \mathrm{~s}$ after the onset of inspiration, with various pressure-support (PS) and ventilatory demand conditions, with Hamilton G5 ventilator software version 1.21 versus version 1.92. 
the respiratory drive, the differences were as much as $18 \%$ : version 1.92 provided much faster triggering than version 1.21. Figure 1 shows the considerable differences in pressurization performance between the 2 software versions. Version 1.92 provides much better pressurization (up to $400 \%$ improvement), especially if demand is high.

Again the intention is not to compare these results to those from Marchese and co-workers, ${ }^{1}$ as we did not use the ASL 5000 lung model and can't compare the experimental settings, but to compare the performance of one software version to the most recent version and to highlight the need to mention which software version was used in a bench evaluation.

Data reported in any study, whether it is a study of ventilator performance or a clinical study, only reflect the time and conditions when the data were collected. Readers should, however, be able to know if the study results can be translated to their own local conditions. Being as precise as possible about the devices compared should help in this matter.

Marc Wysocki

Medical Research

Hamilton Medical

Bonaduz, Switzerland

Michael Kistler

Gion Durisch

Engineering Department

Hamilton Medical

Bonaduz, Switzerland

Paul Garbarini

Robert Hamilton

Hamilton Medical

Reno, Nevada

\section{REFERENCES}

1. Marchese A, Sulemanji D, Chipman D, Villar J, Kacmarek RM. Performance of current ICU ventilators during pressure and volume ventilation. Respir Care 2011; 56(7):928-940.

2. Richard JC, Carlucci A, Breton L, Langlais $\mathrm{N}$, Jaber S, Maggiore S, et al. Bench testing of pressure support ventilation with three different generations of ventilators. Intensive Care Med 2002;28(8):1049-1057.

\section{The authors respond:}

We thank Marc Wysocki and associates for their letter. We totally agree with their concern regarding the specific ventilator software evaluated. However, manufacturers rarely inform us of the specific version they provide for evaluation. The ventilators in our study, except the Covidien PB840 and the Dräger Evita XL, were provided for evaluation by the manufacturers. The Hamilton G5 ventilator was provided to us for evaluation by Marc Wysocki. But none of the manufacturers made it a point to indicate that we should list their ventilator's software version.

We know that every ventilator company is continually upgrading their products and that new software is introduced regularly, and it is as much the obligation of the manufacturer as the researcher to provide the appropriate software version when a ventilator is sent for evaluation.

Regarding the differences in data between Hamilton's evaluation of the G5 and our evaluation, the biggest issue is the evaluation method: the ASL 5000 lung model versus the Michigan Instruments Training and Test Lung. We would always expect the results to be poorer with the ASL 5000, because the Michigan Instruments Training and Test Lung can only evaluate airway pressure changes, whereas the ASL 5000 can evaluate simulated pleural-pressure changes, so all pressures will exhibit a greater change, and time will always be longer with the ASL 500. However, we tested all the ventilators under the same exact settings, and, although the individual findings for a particular ventilator may differ based on the lung model, the comparison of performance across different ventilators should not be affected by the lung model used.

\section{Robert M Kacmarek PhD RRT}

FAARC

Respiratory Care Department Massachusetts General Hospital Boston, Massachusetts

Dr Kacmarek has disclosed relationships with Covidien, Dräger Medical, General Electric, Hamilton Medical, and Newport Medical, Maquet, and KCI.

\section{Is Noninvasive Ventilation Possible Only in New Jersey?}

We read with interest, "Not to Invade: A Better Strategy," an editorial in the June 2011 issue of RESPIRATORY CARE, ${ }^{1}$ concerning the paper "Duchenne Muscular Dystrophy: Continuous Noninvasive Ventilatory Support Prolongs Survival."2 The latter outlined a new protocol for patients who require continuous ventilatory support, in many cases for decades, but managed entirely noninvasively and even extubated and decannulated to full noninvasive ventilation (NIV) when "unweanable." The editorial stated that, "Supporting full-time NIV in the manner that Bach and Martinez did clearly involves a commitment to the support of NIV respiratory management that may not be available at other medical centers." This, of course, is true, but is it not the point of academic medical journals to provide the information necessary to institute beneficial advances at other institutions?

A 2011 study by Ishikawa et al reported significantly greater life expectancy with NIV than with tracheostomy ventilation (38.6 years versus 28.9 years, respectively, $)^{3}$ in part because of the ancillary techniques permitted by NIV, such as glossopharyngeal breathing, breath-stacking, and mechanically assisted coughing, while avoiding life-threatening complications of tracheostomy. ${ }^{4}$ It is true that NIV requires an expert term who can manage both adult and pediatric patients in both the chronic and acute care settings, but, considering the benefits to longevity and quality of life, we feel that this should be the goal of every clinician who specializes in the treatment of patients with Duchenne muscular dystrophy or other neuromuscular disorder.

\section{Ondrea McKay, Medical Student John R Bach MD \\ New Jersey Medical School Newark, New Jersey}

The authors have disclosed no conflicts of interest.

\section{REFERENCES}

1. Benditt J, Boitano. Not to invade: a better strategy. Respir Care 2011;56(6):878.

2. Bach JR, Martinez D. Duchenne muscular dystrophy: continuous noninvasive ventilator support prolongs survival. Respir Care 2011;56(6):744-750.

3. Ishikawa Y, Miura T, Ishikawa Y, Aoyagi T, Ogata H, Hamada S, Minami R. Duchenne muscular dystrophy: survival by cardio-respiratory interventions. Neuromuscular Disorders 2011;21(1):47-51.

4. Bach JR. Management of patients with neuromuscular disease. Philadelphia, PA. Hanley and Belfus; 2004. 